\title{
Perinea Trauma during Childbirth: Socio Demographical Aspect and Management at Obstetrical Gynecology Department Donka National Hospital (Guinea-Conakry)
}

\author{
0. Baldé1, M. H. Diallo1*, I. Sylla², M. N. Mamy¹, A. B. Barry¹, I. S. Baldé2, A. D. Diallo3 , M. D. Baldé1, \\ N. Keita1 \\ ${ }^{1}$ University Department of Gynecology-Obstetrics, Donka National Hospital, Conakry, Guinea \\ ${ }^{2}$ University Department of Gynecology-Obstetrics, Ignace Deen National Hospital, Conakry, Guinea \\ ${ }^{3}$ Visceral Surgery Department Donka National Hospital, Conakry, Guinea \\ Email: *hadydiallo2002@yahoo.fr
}

How to cite this paper: Baldé, O., Diallo, M.H., Sylla, I., Mamy, M.N., Barry, A.B., Baldé, I.S., Diallo, A.D., Baldé, M.D. and Keita, N. (2019) Perinea Trauma during Childbirth: Socio Demographical Aspect and Management at Obstetrical Gynecology Department Donka National Hospital (Guinea-Conakry). Open Journal of Obstetrics and Gynecology, 9, 1486-1491.

https://doi.org/10.4236/ojog.2019.911144

Received: October 8, 2019

Accepted: November 11, 2019

Published: November 14, 2019

Copyright $\odot 2019$ by author(s) and Scientific Research Publishing Inc. This work is licensed under the Creative Commons Attribution International License (CC BY 4.0).

http://creativecommons.org/licenses/by/4.0/

\begin{abstract}
Perineal trauma is a non-surgical solution of continuity of posterior perineal committing under the effect of a violent exertion during childbirth. It occurs at the time of disengagement, either from the head or the posterior shoulder. Objectives: To calculate the perinea trauma during childbirth, describe the socio demographic profile of the women in childbed, identify contributory effects and appreciate the maternal prognostic. Methodology: It was a prospective study, descriptive type of 6 months (from May 19 to November 20, 2014). It took place at the maternity ward of Donka National Hospital. It concerned all received parturient, women in bed of a single fetus in the unit and having had a perineum traumatism. The real ones were epidemiologic, therapeutic clinical and prognostic. Results: We have recorded 110 perinea traumatism cases over 3496 childbirth let say a frequency of $3 \%$. The socio demographic profile of the woman who did perinea traumatism was a teenager (42.7\%), professional occupation (29.1\%), married (88.2\%), schooled, secondary and Technical level (42.7\%), primary (70\%) having had more than 3 prenatal consultations (73.6\%). Contributory effects were: prim parity, young age, instrumental extraction by obstetrical forceps and the fetal weight between 2500 to $3999 \mathrm{~g}$. Surgical management was (100\%). The following were simple in $88.2 \%$ cases versus $11.8 \%$ of complications. Conclusion: The reduction of this frequency requests systematical practice and corrects recentered prenatal consultations and the respect of episiotomy indications.
\end{abstract}




\section{Keywords}

Perinea Traumatism, Epidemiology, Management, Donka

\section{Introduction}

The perinea trauma is a continuous solution non surgical of the posterious commeasure of the perineum under the effect of violent efforts during childbirth [1]. It occurs during the release, either the head or the posterious shoulder. Perinea trauma from obstetrical has always existed and continues to give real issues. These tears are due to young primipara and excised women, second- and third-degree [1] [2] [3]. The lesions can be serious in $6 \%$ of the cases, the concerned the external sphincter of the anus (third degree) or anal channel itself (fourth degree) and are sources of anal incontinence in 10\% - 47\% of the cases [4]. Sometimes there are very invalidate leading to obstetrical fistula (urinary and digestives) and static pelvienne troubles [2] [5]. The frequency varies in accordance with the countries: in the USA 3\% in 2008 [6], in France 5.7\% in 2011 [7], in Tunis $15 \%$ of complete trauma and complicated in 2003 [2], in Congo $5.3 \%$ in 2005 [8], in Ivory Coast $10 \%$ in 2008 [9], in Guinea $11.1 \%$ in a hospital of level second (CMC Matam) after the monitoring findings of 2008. The objective was to calculate the perinea trauma frequency, determine the socio demographic profile of women in bed, identify factors favoring and appreciate maternal prognostic.

\section{Methodology}

This was a prospective, transversal study of 6-month (from May 19 to November 20 , 2014). It concerned all the parturient received, delivered from a single fetus in the service and having had trauma of the perineum. The recruitment was exhaustive. The variables were socio demographic (age, occupation, marital status, level of Education, parity and pre-natal consultations, clinical (end of pregnancy, expulsion presentation, episiotomy, service providers, trauma type, factors favoring, fetal weight), therapeutic and prognostics.

The perineal tear of the first degree, said simple or incomplete, has been defined by cutaneous and muscular involvement, the sheath of the external sphincter of the anus remains intact \pm superficial muscle of perineum (especially bulbocavernous muscle).

The perineal tear of second degree or completed was defined by a tear of the external sphincter, the internal sphincter remains intact.

Complicated third-degree tear or complicated perineum was defined by a complete tearing of the anal sphincter, tearing of the anal mucosa with opening of the anal canal.

The informed consent of patients has been obtained.

We had obtained the prior approval of the national ethics committee. 
During the realization of this work we encountered some difficulties to know:

- the occurrence of the Ebola virus disease with the psychosis that reigned in Donka has decreased the number of women giving birth in Donka;

- the disrespect of the appointments for the control with the sixth and the forty second of the post partum.

\section{Results}

1) Frequency: We collected 110 parturient having had perinea trauma over 3496 deliveries, let say $3 \%$.

2) Socio demographic variables: (Table 1 and Table 2)

a) Age: Forty seven (47) women in bed over 110 (42, 7\%) and thirty two (32) over $110(29.1 \%)$ were respectively from 15 to 19 and 20 to 24 years.

b) Occupation: Thirty two (32) patients over 110 (29.1\%) had occupational activity and thirty (30) over $110(27,3 \%)$ were students and pupils.

c) Marital Status: Ninety seven (97) patients over 110 (88.2\%) were married versus $11.8 \%$ of bachelors.

d) Level of Education: forty seven (47) patients over 110 (42.7\%) were secondary and technical and twenty seven (27) over 110 (24.6\%) were no educated.

e) Parity: Seventy seven (77) sick over 110 (70\%) were on their first childbirth and $24.5 \%$ second and third.

f) Prenatal consultation: Eighty one (81) patients over 110 (73.6\%). Have had three prenatal visits and $15.5 \%$, only one.

3) Clinical variables:

a) End of pregnancy: One hundred and four (104) parturient over 110 $(94.5 \%)$ were towards the end of pregnancy versus $5.5 \%$ for having gone beyond.

b) Presentation: In 97 cases over $110(89.1 \%)$ the presentation was cephalic versus $10.9 \%$ of seats.

c) Expulsion: for ninety (90) parturient over $110(81.8 \%)$ the expulsion was spontaneous and $18.2 \%$ by forceps.

d) Episiotomy: thirty women in bed (30) over 110 (27.3\%) have had episiotomy versus $72.7 \%$.

e) Service Providers: Twenty childbirth (20) over 110 (18.2\%) were practiced by doctors versus $81.8 \%$ for midwives.

f) Trauma Type: Eighty one (81) trauma over 110 (73.6\%) were first degree and twenty eight over 110 (25.5\%) Second Degree.

g) Factors favoring: In 49 cases over 110 (44.5\%) fetal factors were found following those of the peri natal with $26.5 \%$.

h) Fetal weight: In 77 cases over 110 (70\%), are weights between 2500 - 3999 $\mathrm{g}$ which favored the trauma and $27.3 \%$ for those of $4000 \mathrm{~g}$ and more.

4) Treatment: the 110 patients had benefited lesions suture.

5) Prognostic: Ninety seven (97) women in bed over $110(88.2 \%)$ had simple suites versus $11.8 \%$ wound dehiscence and suppuration. 
Table 1. Age distribution.

\begin{tabular}{ccc}
\hline age range & Number of cases of perineal trauma & Percentage (\%) \\
\hline Inferior 15 years & 3 & 2.73 \\
$15-19$ years & 47 & 42.72 \\
$20-24$ years & 32 & 29.09 \\
$25-29$ years & 20 & 18.18 \\
$30-34$ years & 4 & 3.63 \\
greater than or equal to 35 years & 4 & 3.63 \\
Total & 110 & $100 \%$
\end{tabular}

Table 2. Distribution according to parity.

\begin{tabular}{ccc}
\hline Parity & Number of cases of perineal trauma & Percentage (\%) \\
\hline first childbirth & 77 & 70 \\
Second and third & 27 & 24.5 \\
fourth and fifth birth & 2 & 2.75 \\
sixth birth and more & 2 & 2.75 \\
Total & 110 & 100 \\
\hline
\end{tabular}

\section{Discussion}

\section{1) Frequency:}

The frequency found in our series is identical to that reported by American Authors [6], but inferior to other literature data [7] [8] [9]. This high frequency in the unit could be related in one hand to its position in the health pyramid of Guinea (level 3) and on the other hand, the majority were teenagers in this sampling.

\section{2) Socio Demographic Characteristics:}

Teenager could be a factor of predisposition of the perineum trauma. In this population the age range 15 to 19 years was predominates (42.7\%). We notice the same in Congo-Brazzaville in 2005 with 33\% [10]. This could be in relation with the customs and mours that support early marriage in our regions. The perineum trauma does not escape any socio professional layer. In our sampling, patients doing liberal activity were more concerned contrary to Gandzien P.C and col. [8] which had found $51 \%$ of the students in 2005. This phenomenon could be linked to the poverty which leads teenagers to turn to these activities to overcome their needs. Married were more with $88.2 \%$. Rather in the Congolese series in 2005, it was bachelors (78\%) [8]. This situation could be favored by the fact that the biggest religions practice in Guinea recognized all marriage as the only legal for reproduction. The educational level could be a predisposition factor or perinea trauma. So in our population, parturient who have vocational and secondary educational level were moore concentrated with $42.7 \%$ followed by the non educated (24.6\%). The remarks were the same in 2005 with the other 
Congolese [8] [10]. The parity could favorise the occurrence of perinea trauma. In our sampling all groups were touched with the highest proportion for the first childbirth (70\%). These findings look like to others of many African authors [9] [11] [12]. This high frequency of trauma with primipare could be explained by the fact that molecular beams and attached are intact and solid with patients in one hand and on the other hand the reticent of some service providers to practice preventive episiotomy.

\section{3) Clinical Variables:}

In our series, $94.5 \%$ of the parturient was at the end contrary to Gandzien P.C.et Col [10] in Congo in 2005 where predominated going beyond term (75\%). All our patients had benefited a prenatal follow up with a predominance of those who have had three prenatal consultations and mores (73.6\%). But can we remind that it's rather the prenatal visit that helps to detect and solve the early issues than the number. The cephalic presentations have occupied the first stage (89.1\%). It could be justified by their predominance among all the presentations (95\%) in one hand and the other, prenatal distension more marked during the expulsion. The expulsion could constitute a predisposition factor of perinea trauma. That is why $18.2 \%$ of our total had benefited instrumental extraction by forceps versus $81.8 \%$ of the unsolicited expulsion. Episiotomy constitutes a complete part of perinea trauma preventive measures, but it is the only one and unique condition for it to be practiced at time and correctly. In our sampling $27.3 \%$ of patients victims of trauma have had episiotomy. In $81.8 \%$ of the cases, was midwife. So the quality of a service alias to the personal skills, but to the volume of the work too. The first degree had recorded the biggest proportion (73.6\%). The remark was similar with the Congolese study in 2005 [10] with $93 \%$. The occurrence of a perineum trauma is very often secondary to a maternal factor or fetal. In our population the fetal factors were more found (44.5\%) followed by perinea (26.5\%). However, for three traumatized over $10(30 \%)$, they are obstetrical manual and childbirth conditions which were explicatory factors. this high rate of fetal factors could be in relation with the fetal microsomy in the occurrence of perinea trauma. However, whatever the factor causing the traumatism, the service provider is very often hold responsible. All birth weight favorise perinea trauma. In our series the weight between 2500 to $3999 \mathrm{~g}$ dominated (70\%) followed by the $4000 \mathrm{~g}$ and more (27, 3\%). Weight inferior to $2500 \mathrm{~g}$ worth care because they are sometimes generators of these lesions.

\section{4) Treatment:}

All the perinea lesions were immediately sutured after the childbirth.

Infection had dominated the followed up layers in our study population with $8 \%$. The remarks were the same in the African literature [2] [10]. The hygiene insuffisance could be an explanation.

\section{Conclusions}

Perinea trauma was frequent in our study. It was favorised by prim parity, young 
age, and instrumental extraction by forceps. The management was surgical (100\%).

The follow up was simple in $88.2 \%$ of the cases versus to $11.8 \%$ of the complications.

The reduction of this frequency requested systematical practice and corrected encountered prenatal consultations and the respect of episiotomy indications.

\section{Conflicts of Interest}

The authors declare no conflicts of interest regarding the publication of this paper.

\section{References}

[1] Bouhouch, H., Chenguiti, A. and Atouani, M. (2001) Prevention of Perineum Obstetrical Tears: Pregnancy and Pathology. Medical Review, 8, 369-370.

[2] Beyrouti, M.I., Beyrouti, R. and Benamar, M. (2007) Contribution to Complete and Complicated Perinea Tears of Obstetrical Origin. Surgical Tunis, 1, 25-30.

[3] Millogo, T.F., Kabas, T.A. and Thieba, B. (2007) Fetal and Maternal Prognostic during Childbirth with Excised Woman. Journal de Gynécologie Obstétrique et Biologie de la Reproduction, 36, 393-398. https://doi.org/10.1016/j.jgyn.2007.03.002

[4] Courtois, L., Becher, P. and Maticot-Baptista, D. (2008) Instrumental Extraction Thierry's Spatules: Perinea Risk Evolution in Accordance with the Release. Journal de Gynécologie Obstétrique et Biologie de la Reproduction, 37, 276-282. https://doi.org/10.1016/j.jgyn.2007.10.006

[5] Alouini, S., Le Maire, B., et al. (2011) Anal Sphincterien Lesions after Natural Childbirth: Risks Factors and Prevention Ways. Liege Medical Review, 66, 545-549.

[6] Beucher, G. (2008) Maternal Complications of Instrumental Extractions: Instrumental Extractions. Journal de Gynécologie Obstétrique et Biologie de la Reproduction, 37, 244-259. https://doi.org/10.1016/S0368-2315(08)74762-8

[7] Grisot, C., Mancini, J. and De Troyer, J. (2011) Perinea Morbidity of Instrumental Extraction by Suction Cup and Spatulas: What's Really Going on? Journal de Gynécologie Obstétrique et Biologie de la Reproduction, 40, 348-358. https://doi.org/10.1016/j.jgyn.2011.03.007

[8] Gandzien, P.C. and Ekoundzola, J.R. (2005) Teenager's Pregnancy and Childbirth at Talangai-Brazzaville Maternity, Congo. Medicine Black Africa, 52, 429-433.

[9] N'guessan, E., Guie, P. and Bamba, B. (2008) Utilization of Stabilise Dakin Cooper for Local Care after Episiotomy Layer and Perinea Tears. Medicine Black Africa, 55, 129-131.

[10] Gandzien, P.C. (2005) Perinea Obstetrical Tears at the Basic Hospital of Talangai-Brazzaville. Medicine Black Africa, 52, 64-66.

[11] Gandzien, P.C. and Ekoundzola, J.R. (2006) Home Childbirth Basic Hospital of Talangai-Brazzaville. Medicine Black Africa, 53, 405-408.

[12] Gondo, D., N'guessan, K. and Boni, S. (2004) Obstetrical Complications of Female Genital Mutilation. Medicine Black Africa, 51, 147-150. 